\title{
Panorama general de la base de datos "Relaciones de comedias en la Nueva España, siglos XVI y XVII"
}

\author{
Overview of the Database "Relaciones de comedias \\ en la Nueva España, siglos XVI y XVII"
}

\author{
Emiliano Gopar Osorio \\ Universidad Nacional Autónoma de México \\ Instituto de Investigaciones Filológicas, México \\ goparemiliano@yahoo.com.mx \\ egopar@colmex.mx
}

\section{RESUMEN}

Este trabajo tiene la finalidad de presentar el diseño de la base de datos: "Relaciones de comedias en la Nueva España, siglos XVI y XVII". Esta herramienta digital tiene como objetivo profundizar en los estudios del discurso narrativo conocido como relación; además, tiene la intención de fungir como un repositorio que reunirá relaciones íntegras provenientes de diversas obras áureas, cuenten o no con una edición moderna. Por una parte, el artículo señala la importancia de esta estrategia dramática en el teatro áureo; por otra, pretende que los futuros usuarios se familiaricen con la información que brinda esta herramienta digital a fin de que puedan utilizarla como un potencial instrumento para futuras investigaciones. El interés del artículo radica en mostrar que la relación es una estrategia dramática que puede estudiarse como un género discursivo inseparable de la obra dramática a la que pertenece, cuya función y características rebasan los límites que hasta ahora se han señalado.

\footnotetext{
${ }^{1}$ Agradezco la beca posdoctoral que me brinda la DGAPA de la Universidad Nacional Autónoma de México para poder realizar el proyecto en el Instituto de Investigaciones Filológicas, bajo la supervisión de la Dra. Ana Castaño. Asimismo, agradezco el apoyo que he recibido durante mi estancia por parte del Programa de Apoyo a Proyectos e Innovación Tecnológica (PAPIT AG00418), "Las literaturas en México en la época novohispana. Historia y corpus multidisciplinario", a cargo de la Dra. Castaño. El diseño de la base de datos debe mucho a las asesorías brindadas por el Ing. Gerardo Iván Miceli León del departamento de computación del Instituto de Investigaciones Filológicas. También debo reconocer mi deuda con Cecilia A. Cortés Ortiz, quien de manera generosa y desinteresada me orientó para la elaboración de esta herramienta digital; una síntesis sobre su trabajo puede consultarse en Cortés (2019: 121-138).
} 


\section{Emiliano Gopar Osorio}

\section{Palabras clave}

Relación, diégesis, espacio, signos actorales, base de datos.

\section{ABSTRACT}

This paper aims to present to desing of the database: "Relación de comedias en la Nueva España, siglos XVI y XVII". This digital tool aims to deepen the studies of narrative discurse known as relación; in adition, it itends to serve as a repository that will bring together integral relaciones from various Golden plays that have or haven't a modern edition. On one hand, the paper points out the dramatic strategy's importance in the Golden theatre; on the other hand, aims to familiarize future users whith the information provided by this digital tool so that they can use it as a potencial instrument for future research. The interest of the article lies in showing that the relacion is a dramatic strategy that can be studied as a discursive genre inseparable from the dramatic play to wich is belongs, whose function goes beyond the limits that have been indicated so far.

\section{KEYWORDS}

Relation, diegesis, space, acting signs, database.

RECEPCIÓN: 28/02/2020

ACEPTACIÓN: 24/03/2020

$\mathrm{L}$ a relación presente en el teatro áureo es un recurso teatral que ha sido escrito no con el fin de representar los hechos ahí evocados, sino para transmitirlo de manera verbal, y así poder recrearlo mediante la imaginación del espectador, con el propósito de que éste vincule los hechos relatados con los acontecimientos que son perceptibles - auditiva y visualmente - por llevarse a cabo en el espacio escénico. ${ }^{2}$ Además de dicha recepción externa, la principal función de la relación se ubica a nivel interno: ofrecer cierta información a un personaje que frecuentemente la desconoce. De esta forma, el dramaturgo garantiza el adecuado desarrollo de la acción en aquellos momentos en los que se necesita hacer extensivo el espacio y el tiempo.

El objetivo principal de este artículo es dar a conocer la base de datos denominada "Relaciones de comedias en la Nueva España, siglos XVI y XVII". Para ello, es

\footnotetext{
${ }^{2}$ El espacio "concretamente perceptible por el público en o las escenas" hace referencia a una realidad doble: "muestra lo que concretamente existe [significante], pero también remite a lo que él simboliza como signo [significado]: habitación: palacio; cuartucho: celda" (Pavis, 1980: 181 y 183).
} 


\section{"Relaciones de comedias en la Nueva España, siglos Xvi y xvII"}

necesario destacar previamente algunos señalamientos en torno al modo en que era apreciada la relación durante el periodo áureo, tanto en la preceptiva como en la práctica teatral, así como algunas definiciones que sobre este recurso han ofrecido algunos estudios modernos. La finalidad de este breve recorrido es, por un lado, llamar la atención sobre la falta de un estudio integral que permita explorar de manera filológica dicho recurso teatral. Por otro lado, se pretende delimitar la relación como género discursivo que depende de la obra dramática a la que pertenece para su análisis, en virtud de que dicho género es el objeto de estudio de la base de datos.

Las preceptivas dramáticas tanto renacentista como del Siglo de Oro daban poca importancia a la función del discurso narrativo en el teatro, pues sus observaciones tendían a considerar la acción como la base de la obra. Basten, como muestra de tal actitud, las palabras de López Pinciano al explicar el origen de la tragedia: "nació de la épica la tragedia y tomó la narración de las personas solamente, dexando la del poeta; lo qual hiziero[n] los trágicos por mouernos los ánimos, que, como dize Horacio, más perezosamente incitan a las orejas las cosas oydas que no las vistas" (López, 1953, epístola 8: 304). Evidentemente, el término narración empleado por el preceptista significa el diálogo de los personajes; por cosas oídas se refiere a la narración, tal como la entendemos en la actualidad. Mientras estima que el discurso narrativo es menos relevante desde el punto de vista de la recepción, asegura que las cosas vistas - es decir, el diálogo de los personajes en escena - repercuten con mayor contundencia sobre el espectador. Tal concepción está lejos de considerar la coexistencia dialéctica entre la acción y el discurso narrativo en la literatura dramática.

Esta perspectiva no es sino una repetición con leves matices de las ideas de Aristóteles, quien había establecido una barrera entre la acción y la narración: "es, pues, la tragedia imitación de una acción esforzada y completa, de cierta amplitud, en lenguaje sazonado, separada cada una de las especies en las distintas partes, actuando los personajes y no mediante relato" (Aristóteles, 1974, cap. 6: 1449b, líneas 24-27). Privilegiar la acción es una idea que se presenta de manera reiterada en la Poética, ${ }^{3}$ de ahí que los comentaristas y traductores de Aristóteles consideren que la acción y la narración son dos aspectos incompatibles en el teatro: el primero es su elemento estructural, mientras que la narración es un discurso ajeno por ser propio de la epopeya.

Pero la práctica literaria a veces sigue derroteros muy distintos de los que marca la preceptiva. Juan de la Cueva, por ejemplo, ofrece un comentario aislado sobre el

3 "La tragedia es imitación, no de personas, sino de una acción y de una vida, y la felicidad y la infelicidad están en la acción, y el fin es una acción, no una cualidad"; "sin acción no puede haber tragedia; pero sin caracteres, sí" (Aristóteles, 1974, cap. 6: 1450a, líneas 15-17 y 24-24, respectivamente). 


\section{Emiliano Gopar Osorio}

discurso narrativo al hablar de la utilidad que en el teatro tiene el empleo de un cierto tipo de versificación:

Esta es la rima otava en quien florece heroica alteza y épica ecelencia, y en dulzura a la lírica engrandece.

$[\ldots]$

No desdeña que en cuentos la apliquemos ni en comedias en largas narraciones ni en las tragedias triste della usemos (Cueva, 1941, epístola II, 152: vv. 94-123).

El autor ya reconoce la presencia de la narración en la comedia y en la tragedia. El adjetivo utilizado - largas - para calificar el tipo de narraciones que merecen transmitirse mediante las octavas connota la presencia de narraciones de menor extensión, que, seguramente, requerían otro tipo de versificación.

Por su parte, Lope de Vega ofrece sugerencias métricas para la elaboración de las comedias, entre las cuales destaca la recomendación para el tipo de metro propio de la relación:

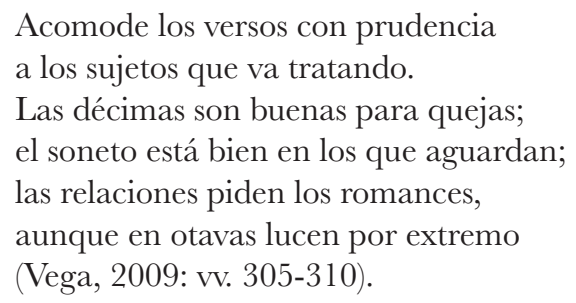

Mientras en Ejemplar poético se justificaba el tipo de verso utilizado, Lope de Vega establece una correspondencia temática con la versificación. Esta situación muestra que en la práctica del Fénix, la relación no constituye un asunto menor, sino que ya es apreciada como una estrategia dramática, puesto que, además de propiciar el desarrollo adecuado de la acción, tiene la finalidad de deleitar mediante la recitación del discurso por parte de los actores.

Para comprender esta finalidad, hay que considerar, como bien lo señalan Luis C. Pérez y Federico Sánchez Escribano, que uno de los "preceptos más importantes [de Lope], quizá el más importante, [es] el entretener" (Pérez y Sánchez, 1961: 189). En este sentido, es lógico suponer que si la longitud alcanzada por ciertas relaciones hubiera provocado la distracción o el disgusto del espectador, el Fénix habría buscado medios para reducirla, en virtud de que tenía muy claro el límite entre deleitar y estorbar el desarrollo de la acción, pues, como conocedor de la retórica, sabía "cuánto en ella se reprenden las digresiones largas" (Vega, 2003: 48). 


\section{"Relaciones de comedias en la Nueva España, siglos xvı y xvıı"}

Desde una perspectiva actual, tal vez sea un poco difícil comprender el deleite que un espectador experimentaba al percibir una relación, pues los directores de escena que modernizan un texto áureo muchas veces suprimen o simplifican los largos discursos narrativos para hacer más inteligible el texto. Lope, en cambio, no tuvo problema con lo extenso de sus relaciones, ${ }^{4}$ él mismo confiesa que, al ofrecer una narración, "hay poeta cómico que se lleva de un aliento tres pliegos de un romance" (Vega, 2003: 49); claramente se trata de un guiño irónico sobre su propia práctica dramática.

A pesar de que en el teatro del Siglo de Oro y, particularmente, en la Comedia Nueva se reconocía la relación como una estrategia dramática de gran importancia, en la actualidad no se cuenta con una definición cabal. El Diccionario de Autoridades ofrece la acepción que concierne a la literatura dramática: "En las comedias es la narración, que sirve de episódio o de explicación del thema de la comedia. Latín. Recitatio comica"; ${ }^{5}$ más que a la relación, esta definición se acerca a cierto apartado de algunas comedias conocido como prólogo o proemio. Por su parte, el Diccionario de la comedia del Siglo de Oro no contempla una entrada para este discurso - a pesar de contar con definiciones para un reducido número de estrategias dramáticas - ; no obstante, habla sobre las funciones de la narración en el teatro, aunque lo hace de manera indirecta en una de las acepciones de romancero: "también puede emplearse, como hace Lope, para evocar situaciones o para anticipar acontecimientos" (Casa, 2002: 263); con tales palabras, se incluye la prospección dentro de sus alcances.

Uno de los problemas al intentar definirla es que siempre se busca simplificar su significado al asociarla, llanamente, con una información de carácter retrospectivo que sirve para contextualizar la acción dramática. En otros casos, como en los tratados de métrica, se da por hecho que el lector conoce su significado y que, por tanto, resulta ocioso ofrecer una definición. ${ }^{6}$ Para evitar confusiones, es necesario aclarar que el fenómeno al que nos referimos es diferente del género histórico conocido como "relación", el cual se caracteriza por ser un "tipo discursivo textualizado" que, al igual que las cartas, se escribe "con la obligación de informar a la Corona y no con la intención de pasar a la dimensión del libro" (Mignolo, 1982: 59). ${ }^{7}$

\footnotetext{
${ }^{4}$ Si las relaciones hubieran aburrido al público o lo hubieran distraído del asunto principal, la extensión de este discurso no hubiera sido tan abundante en el teatro lopesco ni en la mayor parte de los dramaturgos áureos.

${ }^{5}$ Diccionario de Autoridades (1737), s. v. RELACión.

${ }^{6}$ Como sucede con Diego Marín al hablar de los usos del romance: "para la relación puramente informativa o lírica, que no produce efecto alguno en la situación dramática, el romance pierde su carácter predominante [...] Igualmente significativo es que Lope prefiriese la redondilla al romance, para relaciones de signo negativo, en que prevalece el desacuerdo o la hostilidad entre los interlocutores" (Marín, 1962: 27).

${ }^{7}$ Walter D. Mignolo añade que el término también se emplea "en contextos en los cuales significa simplemente relato o informe" (Mignolo, 1982: 59).
} 


\section{Emiliano Gopar Osorio}

Contrario a lo anterior, desde nuestra percepción, la relación era una de las partes que más despertaba emociones en el espectador. Un fenómeno que habla del regocijo provocado por este tipo de discursos es la selección de relaciones extraídas de las comedias, así como su edición mediante pliegos sueltos que surgió a finales del siglo XVII. ${ }^{8}$ Ante la prohibición de funciones teatrales, surgieron tertulias en las que la atracción principal era la recitación de estas relaciones. ${ }^{9}$

En torno a este fenómeno editorial, se hicieron algunas reflexiones sobre el discurso que es objeto de nuestro estudio. Pese a que en los pliegos sueltos están descontextualizadas de la acción dramática, Gillet reconoce que, desde la época de Lope, las relaciones "had begun to draw to themselves much of the essencial information, especially detailed retrospective information deemed necesary to a proper underestanding of the play, and were beginning to assume inordinate length" (Gillet, 1922: 455). ${ }^{10}$ Siguiendo las opiniones de Gillet, García de Enterría ofrece una definición para este tipo de relaciones:

Todas las "relaciones" [...] son, por sí mismas, una parte definida de la comedia, inteligibles ellas aisladas sin que sea necesario leer la obra entera para entender lo que se nos relata. Son de carácter totalmente narrativo, expositivo; nos cuentan lo que no puede verse en escena, pero necesariamente ha de saberse para entender el juego dramático, o definen la personalidad de un personaje importante de la obra (García, 1973: 353).

Sus observaciones son válidas para el discurso difundido en pliegos sueltos, pero tratarlo como un discurso autónomo genera dudas acerca de su función dentro de su contexto original. El estudio de la relación debe estar ligado al de la obra a la que pertenece para no correr el riesgo de relativizar su función cuando se le separa de su contexto; la autora misma pone énfasis en la utilidad que tiene la relación en el seno de la obra al señalar que "nos sitúan en el corazón de la intriga dramática para poder entenderla completamente al contársenos lo que no hemos sabido porque no habíamos podido ver o captar hasta entonces" (García, 1973: 356).

\footnotetext{
${ }^{8}$ Entre otros autores, Joseph E. Gillet (1922 y 1924), María Cruz García de Enterría (1973), Rafael González Canal (2010) y Jaime Moll (2011) ofrecen testimonios de este tipo de difusión.

${ }^{9} \mathrm{Al}$ referirse al tomo facticio que recoge pliegos sueltos impresos en Sevilla entre $1729 \mathrm{y}$ 1941 (Biblioteca Nacional de Madrid, colección Gayangos, signatura R24.105), Jaime Moll considera que una de las principales causas del surgimiento de los pliegos que contenían "relaciones de comedias" fue el cierre de los teatros ocurrido en aquella ciudad. Y ante dicha situación, el "público enfervorizado por el teatro [...] reacciona creando este sustitutivo: la recitación de fragmentos de comedias en sus reuniones caseras" (Moll, 2011: §9).

10 "habían comenzado a atraer a sí mismas gran parte de la información esencial, especialmente la detallada información retrospectiva que se consideraba necesaria para la adecuada comprensión de la obra, y comenzaban a adquirir una dimensión desmesurada" [La traducción es mía].
} 


\section{"Relaciones de comedias en la Nueva España, siglos xvi y xvII"}

Quienes han observado este fenómeno editorial han señalado la falta de un estudio monográfico sobre esta forma de difusión (González Canal: 29). Pero antes de ese estudio, es necesario emprender uno que atienda la relación en su contexto original, la obra dramática.

Para poder comprender los usos de la relación en la obra a la que pertenece, es conveniente considerar que la estrategia dramática comparte rasgos con los géneros discursivos, ${ }^{11}$ pues presenta las siguientes características: es un eslabón en la cadena de la comunicación dentro de una esfera determinada de la realidad discursiva más amplia, la obra de teatro; siempre está destinada a alguien, de quien se espera una respuesta, pues forma parte de un mecanismo dialógico; posee cierto carácter cerrado; casi siempre es una respuesta a una proposición anterior; posee un realizador específico, quien manifiesta su individualidad mediante su visión de mundo, lo que dota al discurso de una intención; dicho enunciador determina el tema, el estilo (la versificación), las coloraciones afectivas y las posiciones valorativas. El acercamiento al género discursivo tiene que tomar en cuenta que éste es parte de los textos que le dan acogida, y no una entidad aislada; sin embargo, al mismo tiempo es posible circunscribir y analizar dicho discurso en sí mismo para comprender, por un lado, su propia poética y, por otro, para enriquecer el conocimiento de la obra a la que pertenece. Tal situación permitiría, a su vez, una comprensión de las funciones generales de la relación en el teatro áureo.

\section{La relación: dialéctica entre el texto dramático y el espectacular}

El género discursivo está presente en la mayoría de las obras dramáticas áureas sin importar su pertenencia a una determinada clasificación genérica; ${ }^{12}$ tampoco hay diferencias significativas entre las obras peninsulares y las novohispanas. El discurso se encuentra en el umbral del texto dramático y del texto espectacular: ${ }^{13}$ las acciones que transmite se ubican espacialmente más allá del espacio escénico y, por tanto, se encuentran fuera del alcance de las leyes que rigen la propia literatura dramática, pero el aspecto verbal - el pilar que lo sostiene - es el elemento que une esa realidad imaginaria con el texto espectacular mediante la voz del personaje durante su transmisión.

${ }^{11}$ Para la definición de género discursivo, véase Bajtín (1999: 248-293).

${ }^{12}$ Es difícil observar relaciones en los entremeses debido a la brevedad de este género.

${ }^{13}$ Para Bobes Naves, el texto dramático se divide en texto literario ("constituido fundamentalmente por los diálogos, pero [...] puede extenderse a toda la obra escrita") y texto espectacular ("formado por todos los signos, formantes de signo e indicios que en el texto escrito diseñan una virtual representación”) (Bobes, 1997: 32). Esta terminología puede generar confusiones, pues ambos forman parte de un texto literario: la obra dramática. Por tal motivo, utilizaré el término texto dramático para referirme a lo que la estudiosa llama texto literario. 


\section{Emiliano Gopar Osorio}

Desde la perspectiva teatral, el término diégesis designa el ámbito imaginario que forma parte del contexto a partir del cual se desarrolla de manera lógica la acción dramática, pues equivale a relato (Pavis, 1980: 137). En este sentido, la información transmitida mediante la relación pertenece al ámbito diegético, al igual que ocurre con el decorado verbal, ${ }^{14}$ con la teichospia ${ }^{15}$ o con las narraciones intercaladas en la literatura dramática, como los cuentos o las anécdotas personales.

Pero diégesis no implica en teatro lo mismo que en el género narrativo. En este último, de acuerdo con Pimentel, el término comprende "el universo espaciotemporal que designa el relato" (Pimentel, 2002: 11); aquí las acciones y los espacios no son vistos por el lector de manera directa, pues éstos se transmiten a través de la intermediación del narrador, quien tampoco se encuentra a la vista del lector. En el teatro, en cambio, las acciones diegéticas siempre están vinculadas con elementos espectaculares que pueden ser percibidos por el espectador, pues los personajes que interactúan durante la transmisión de la acción diegética, como ocurre al ofrecerse una relación, casi siempre se ubican en el espacio mimético ${ }^{16}$ (aunque en algunas ocasiones el personaje transmisor puede estar ubicado en un espacio extensivo). ${ }^{17}$ Es decir, a pesar de que la atención del espectador se centra en la narración que percibe de manera auditiva, la presencia de los personajes, que ocupan un lugar en el espacio, también influye en la recepción: las entonaciones, los movimientos, los gestos y los mismos cuerpos están llenos de significados dramáticos. ${ }^{18}$

${ }^{14}$ De acuerdo con Pavis, se trata del "decorado descrito o sugerido no por medios visuales, sino por el comentario de un personaje [...] La técnica del decorado verbal es sólo posible en virtud de una convención aceptada por el espectador: éste tiene que imaginarse el lugar escénico y la transformación inmediata del lugar desde el momento en que es anunciada" (Pavis, 1980: 117). Por su parte, Arellano complementa los alcances de la técnica al señalar que "consiste en ampliar los límites del escenario para integrar en ellos objetos, paisajes y acciones que no pueden representarse materialmente en las tablas" (Arellano, 1995: 429).

15 "Medio dramático por el cual un personaje describe lo que sucede tras los bastidores en el instante mismo en el que el observador lo relata (extra-escena)" (Pavis, 1980: 497).

${ }^{16} \mathrm{Al}$ hablar de un espacio diegético, necesariamente se tiene que hablar de uno mimético (González, 2006: 68); ambos forman parte del espacio dramático — el espacio de la ficción-, sólo que el primero no es visible para el espectador, mientras que el segundo sí lo es, ya que mimesis, en terminología teatral, implica la "imitación de un acontecimiento en palabras" (Pavis, 1980: 137), es decir, la presentación de esta imitación ante el espectador.

17 "Un espacio invisible, pero coextensivo del espacio escénico. Es el espacio contiguo de los bastidores, tanto en el mundo virtual como en el real" (Corvin, 1997: 203).

${ }^{18}$ Por supuesto, también el vestido y los elementos escenográficos tienen tales significados. Desafortunadamente, el trabajo actoral que facilita dicha significación en el espacio escénico no es perceptible para el lector del teatro áureo, sin embargo, el propio texto dramático ofrece indicios que denotan la actividad actoral. 


\section{"Relaciones de comedias en la Nueva España, siglos Xvi y xvII"}

Los movimientos de los personajes en el aquí y ahora de la virtual representación ayudan a reforzar las palabras del personaje que habla, pero también remarcan los sentimientos experimentados por quien escucha: uno trata de persuadir y el otro se conmueve. Imposible pensar que durante una tirada de 200 o más versos los personajes permanecieran estáticos. En este sentido, es evidente que la transmisión de una relación implica una dialéctica entre el texto dramático y el espectacular.

Los estudios en torno a este género discursivo no han tomado en cuenta el ámbito espectacular, sólo se han limitado a tratarlo como una entidad meramente verbal. Ante tal carencia, he diseñado una base de datos en la que se reúnen relaciones provenientes de diversas obras dramáticas que tienen una edición moderna; en caso de que no cuenten con ella, los textos se editan con apego a los criterios de edición de PROLOPE, mismos que pueden consultarse en línea. ${ }^{19}$ De manera generalizada, la herramienta digital describe las partes constitutivas más relevantes de la relación a nivel discursivo y espectacular, ofrece una contextualización de la acción dramática a la que pertenecen y brinda una categorización sobre sus funciones.

El objetivo de la base de datos es que el usuario pueda llevar a cabo búsquedas diversas (por palabras clave, por motivos, mediante la clasificación regida por criterios espaciales y temporales, por el tipo de verso empleado, por el tipo de fórmulas de inicio o de cierre, etc.). De esta manera, se pretende trazar nuevas sendas para ampliar los estudios sobre la estrategia dramática que tome en cuenta que se trata de un género discursivo inseparable de la obra a la que pertenece. En última instancia, la razón de ser de la base de datos es el conocimiento de los usos y funciones de la relación que redunde en la ampliación de nuestra perspectiva sobre el teatro áureo.

La herramienta digital de investigación está en funcionamiento desde marzo de 2021 y se aloja en "Historia de las literaturas en México. Siglos XVI al XVII", base de datos en MySQL (MaríaDB) que próximamente estará dada de alta en el sistema Google Analytics del Instituto de Investigaciones Filológicas de la UNAM. Se puede consultar en esta dirección: https://www.iifl.unam.mx/hlmnovohispana/\#/PresentacionRelaciones. La base de datos forma parte del Programa de Apoyo a Proyectos e Innovación Tecnológica (PAPIT AG00418), "Las literaturas en México en la época novohispana. Historia y corpus multidisciplinario", a cargo de la Dra. Ana Castaño. A continuación, describo la estructura en Access que hizo posible la conformación de la herramienta digital con el fin de fomentar su utilización.

${ }^{19}$ Véase: http://prolope.uab.cat/obras/criterios_y_materiales_para_la_edicion.html. 


\section{Emiliano Gopar Osorio}

\section{Descripción de la base de datos}

La base de datos "Relaciones de comedias en la Nueva España, siglos XVI y XVII" está conformada por veinte tablas, que se dividen en cuatro grupos: una tabla principal denominada Texto; dos tablas para la recopilación de elementos vinculados con el texto espectacular; nueve tablas catálogos (cuya función es crear un repositorio de datos para evitar que se repitan innecesariamente), y ocho tablas relacionales (que sirven para establecer vínculos ente la tabla principal — Texto - y los catálogos). El diseño general se puede resumir de la siguiente manera:

\begin{tabular}{|c|c|c|c|}
\hline Tabla principal & $\begin{array}{l}\text { Tablas elementos } \\
\text { no discursivos }\end{array}$ & Tablas catálogos & Tablas relacionales \\
\hline 1 Texto & $\begin{array}{l}1 \text { Signos actorales } \\
2 \text { Vínculos }\end{array}$ & $\begin{array}{l}1 \text { Bibliografía } \\
2 \text { Princeps } \\
3 \text { Clasificación } \\
4 \text { Elaborador } \\
5 \text { Motivos } \\
6 \text { Palabras clave } \\
7 \text { Soporte } \\
8 \text { Tipo de acción } \\
9 \text { Versificación }\end{array}$ & $\begin{array}{l}1 \text { Princeps_Bibliografía } \\
2 \text { Texto_Clasificación } \\
3 \text { Texto_Elaborador } \\
4 \text { Texto_Motivos } \\
5 \text { Texto_Palabras clave } \\
6 \text { Texto_Soporte } \\
7 \text { Texto_Tipo de acción } \\
8 \text { Texto_Versificación }\end{array}$ \\
\hline
\end{tabular}

\section{Tabla texto}

Esta es la tabla principal. Su propósito es, por un lado, almacenar las relaciones provenientes de diversas obras dramáticas para que puedan ser consultadas de manera íntegra; por otro lado, ofrecer la descripción de sus partes constitutivas a nivel discursivo; dichas descripciones contemplan tanto información dramática (la referente al actuar de los personajes que intervienen en la transmisión de la relación) como diegética (la referente a los hechos transmitidos en la relación). Para ello, la tabla consta de 27 campos; la mayoría de ellos están diseñados para almacenar información, sólo los campos 13, 14, 23 y 24 son predeterminados, es decir, sólo permiten la elección de los términos sí o no (por ejemplo, el último de estos campos informa si la acción dramática es o no nocturna).

La tabla comienza con el campo Id_Texto, un número de identificación único e irrepetible asignado de manera automática por la base de datos a cada relación. ${ }^{20}$ A partir de este número, se encuentran los campos que la integran, mismos que se des-

\footnotetext{
${ }^{20}$ Cabe señalar que todas las tablas inician con un Id para cada registro que se introduzca en ellas, la razón de ser de este elemento se explicará en la sección "Relación entre las tablas".
} 


\section{"Relaciones de comedias en la Nueva España, siglos xvi y xvII"}

criben a continuación: 1) la Narratio (en este espacio se alojan las relaciones); 2) Nombre; ${ }^{21}$ 3) Argumento (breve descripción del contenido del relato); 4) Nombre de la acción; 5) Nombre del discurso (estos dos últimos campos recuperan los nombres señalados si éstos aparecen de manera explícita en la obra); 6) Acción dramática; 7) Texto marco anterior; 8) Texto marco posterior (estos tres últimos campos ofrecen el contexto dramático en el que se inserta la relación); 9) Fórmula de apertura; 10) Fórmula de cierre; 11) Bibliografía; 12) Ubicación; ${ }^{22}$ 13) Verso; 14) Prosa; 15) Personaje receptor; 16) Personaje transmisor; 17) Personaje emisor; ${ }^{23}$ 18) Personajes referidos; 19) Espacio dramático abierto; 20) Espacio dramático cerrado; 21) Espacio diegético abierto; 22) Espacio diegético cerrado; 23) Acción diurna; 24) Acción nocturna; 25) Tiempo dramático; 26) Momentos referidos, y 27) Fecha de elaboración del registro en la base de datos.

\section{Tablas para la recopilación de elementos vinculados con el texto espectacular}

\section{Tabla signos actorales}

Hasta el momento, los estudios de teatro áureo que se han ocupado de los elementos actorales a partir del texto dramático han centrado su atención en los signos lexicalizados que se presentan, principalmente, durante las acciones dialogadas (Rodríguez, 1998: 373-382). No hay un enfoque, en cambio, que se ocupe de aquellos signos que denotan el trabajo actoral durante los momentos en los que el personaje toma la palabra para crear un ambiente diegético. Si bien es cierto que la transmisión de una relación implica una evidente relajación de la acción dramática en curso, no hay por qué pensar que en dicha situación disminuya la labor actoral del transmisor o del receptor. Ante tal situación, esta tabla recaba los signos lexicalizados y los no lexicalizados presentes durante la transmisión de una relación y que pertenecen al ámbito dramático, pero también los que se encuentran en el ámbito diegético.

La tabla está compuesta por 16 campos, mismos que se describen a continuación: 1) gestos dramáticos lexicalizados, ${ }^{24}$ 2) movimientos corporales dramáticos

${ }^{21}$ Independientemente del Id, cada relación es identificada mediante la asignación de un nombre que incluye un número consecutivo, las iniciales del autor y algunas palabras que denotan el nombre de la obra. Por ejemplo: "01_MdCS_elgallardo" es el nombre para la primera relación, que pertenece a la obra cervantina El gallardo español.

${ }^{22}$ Ofrece el número de acto, los versos, los folios o las páginas en los que se ubica la relación.

${ }^{23}$ El emisor sólo se consigna cuando se muestra de manera explícita en el texto.

${ }^{24}$ En éste y en todos los campos denominados gestos, se recopilan los signos que hacen referencia a la mímica gestual y a aquellos que tienen que ver con sentimientos, estados de ánimo y emociones. Por signo lexicalizado se entiende aquel que por medio de la verbalización 


\section{Emiliano Gopar Osorio}

lexicalizados; 3) entonaciones de voz dramáticas lexicalizadas; 4) movimientos de vista dramáticos lexicalizados; 5) gestos diegéticos lexicalizados; 6) movimientos corporales diegéticos lexicalizados; 7) entonaciones de voz diegéticas lexicalizadas; 8) movimientos de vista diegéticos lexicalizados; 9) gestos dramáticos no lexicalizados; ${ }^{25} 10$ ) movimientos corporales dramáticos no lexicalizados; 11) entonaciones de voz dramáticas no lexicalizadas; 12) movimientos de vista dramáticos no lexicalizados; 13) gestos diegéticos no lexicalizados; 14) movimientos corporales diegéticos no lexicalizados; 15) entonaciones de voz diegéticas no lexicalizadas, y 16) movimientos de vista diegéticos no lexicalizados.

\section{Tabla vínculos}

En esta tabla se ofrecen los vínculos discursivos entre la relación y la acción dramática. Los elementos discursivos aquí recopilados implican una dialéctica entre el texto dramático y el texto espectacular, pues representan una pausa en el relato y un momentáneo regreso a la acción dramática que necesariamente tendría que ser reforzado con el trabajo actoral, mismo que es evocado casi siempre mediante signos no lexicalizados. El elemento que funciona como vínculo puede pertenecer al diálogo de los personajes, antes o después de la relación, puede aparecer en el transcurso del relato e, incluso, puede estar apoyado mediante didascalias. Cabe señalar que los elementos de esta tabla no han sido advertidos en ningún estudio, por tal motivo se precisa enunciarlos en este espacio.

La tabla está integrada por los 10 campos que se mencionan a continuación: 1) vínculos visuales, 2) vínculos auditivos, y mediante múltiples referencias: 3) al presente de la (virtual) representación, 4) al discurso, 5) al proceso de enunciación, 6) al proceso de elaboración del discurso, 7) al canal de comunicación, 8) apelativas al receptor del discurso, 9) apelativas al transmisor del discurso por parte de un personaje evocado, 10) apelativas al espectador.

\section{Tablas catálogos}

\section{Tabla bibliografia}

Ofrece 13 campos que permiten la identificación de cada obra. Estos campos son: 1) autor, 2) obra, 3) editor, 4) responsable de la edición paleográfica, 5) traductor, ${ }^{26}$ 6) edi-

señala "exactamente lo que se desea sea mirado u observado" en la virtual representación (Rodríguez, 1998: 373).

${ }^{25}$ Es decir, que no aparecen verbalizados, pero que se pueden deducir a partir del diálogo de los personajes o de las didascalias.

${ }^{26}$ Algunas de las obras consignadas están escritas en latín. 


\section{"Relaciones de comedias en la Nueva España, siglos xvı y xvıı"}

torial, 7) ciudad, 8) año, 9) nombre de la obra colectiva, 10) tomo, 11) colección, 12) número de páginas, 13) Id de la edición princeps. La tabla relacional Princeps_Bibliografía permite la vinculación entre la bibliografía moderna y la edición del texto base. Su conexión con la relación se brinda mediante el campo número 12 de la tabla Texto.

\section{Tabla princeps}

Esta tabla sirve para indicar qué obra ha sido tomada como texto base, independientemente de que cuente o no con una edición moderna. Está compuesta por 11 campos, mismos que se enlistan a continuación: 1) autor, 2) título, 3) librero o casa editorial, 4) ciudad, 5) impresión a costa de, ${ }^{27}$ 6) año de la publicación o de la elaboración del manuscrito, 7) nombre del tomo en el que se integra la obra, 8) número de páginas o folios, ${ }^{28}$ 9) biblioteca de resguardo, 10) clasificación o número de manuscrito, y 11) archivo digital. Cuando la obra cuenta con una reproducción digital abierta al público por parte de alguna biblioteca o institución educativa, el último campo sirve para proporcionar la liga correspondiente.

\section{Tabla clasificación}

Para poder estudiar la relación de manera sistematizada, es necesario agruparla en categorías. Cabe señalar que, hasta el momento, los estudiosos han clasificado el género discursivo desde una perspectiva temática. ${ }^{29}$ La tabla está integrada sólo por dos campos, que ofrecen, respectivamente, un número asignado a cada categoría (que se brinda de manera consecutiva en números romanos) y las características de cada categoría. La información aquí contenida brinda un aporte significativo a los estudios del teatro áureo, pues permite la agrupación del género discursivo a partir de la ubicación espaciotemporal; por tal motivo, aprovecho esta ocasión para dar a conocer las categorías que sirven de base para nuestra clasificación.

I Narración que presenta sucesos que van ocurriendo en un espacio imaginario (en un espacio extensivo o en uno diegético) mientras son recreados por un personaje

${ }^{27}$ Aquí se señala quién es el responsable de sufragar los gastos de la impresión.

${ }^{28}$ Se utiliza sólo cuando la obra pertenece a un volumen colectivo.

${ }^{29}$ Diego Marín, por ejemplo, ofrece los siguientes tipos: la relación de carácter afectivo; la puramente informativa o lírica; la de signo negativo o de tono polémico y resultado negativo; las "relaciones en romance para hacer una descripción brillante de algún desfile o fiesta cortesana en el estilo enumerativo del cronista oficial que Lope aspiraba a ser"; "las relaciones al final de la comedia para deshacer el enredo y producir el desenlace"; las "partes narradas por ocurrir fuera de la escena", y "el diálogo-comentario sobre algún hecho inmediato", al que también denomina como soliloquio factual con tensión dramática, etc. (Marín, 1962: 27-35). 


\section{Emiliano Gopar Osorio}

- o más de uno - ubicado en el espacio mimético. II Narración de hechos ocurridos antes de la virtual representación que están vinculados con la acción dramática. III Narración de hechos que se omiten en el espacio mimético y que se llevan a cabo en cualquier momento de la virtual representación. IV Narración de sucesos atemporales cuya ubicación espacial puede o no ser diferente con respecto al espacio dramático. ${ }^{30} \mathrm{~V}$ Narración de hechos futuros que se supone han de realizarse después del tiempo de la virtual representación. VI Narración con carácter mimético; se trata de aquellas narraciones que ofrecen nuevamente los hechos que tuvieron lugar en el espacio mimético y que, por tanto, fueron percibidos por el espectador. Cabe señalar que una relación puede pertenecer a más de una categoría.

\section{Tabla elaborador}

La tabla señala el nombre del responsable del registro de relaciones en la base de datos. Por el momento, la tabla no tiene mayor trascendencia, pues fue diseñada pensando en la posible integración de colaboradores en el proyecto.

\section{Tabla motivos}

Como su nombre lo indica, contiene los motivos literarios que están presentes en las relaciones. Los motivos provienen de S. Thompson, Motif-Index of Folk-Literature: A Classification of Narrative Elements in Folktales, Ballads, Myths, Fables, Medieval Romances, Exempla, Fabliaux, Fest-Books, and Local Legends, que se encuentra en línea: www.ruthenia.ru/folklore/ thompson/. Conforme se hace el registro de las relaciones en la base de datos, se lleva a cabo la búsqueda de los motivos que aparecen en cada una de ellas. Es por esa razón que no hay una lista predeterminada de motivos consultados, ya que ésta se va incrementando de manera proporcional a la variación de los temas presentes en las relaciones.

\section{Tabla palabras clave}

La intención de esta tabla es ofrecer la posibilidad de búsquedas de carácter temático. La tabla contiene alrededor de 220 palabras clave, mismas que se relacionan con los elementos más comunes en la dramaturgia del Siglo de Oro. El número de palabras puede aumentar de manera proporcional al incremento de temas encontrados

${ }^{30}$ Entre los que se consideran atemporales están los hechos imaginarios o ilusorios, como los engaños para provocar enredo, porque sólo tienen lugar en la imaginación de quien los crea (y casi siempre son recibidos como verdaderos por quienes oyen el relato y caen en el engaño), aunque hayan sido inventados mientras la acción dramática está en curso. 


\section{"Relaciones de comedias en la Nueva España, siglos xvı y xvıı"}

durante el registro de nuevas relaciones en la base de datos. La tabla está conformada por dos campos: el primero aloja las palabras clave y el segundo ofrece una definición sólo cuando la palabra posee un significado diferente del actual, cuando se trata de un término que ha perdido su significado o cuando hay necesidad de delimitar el significado para no caer en ambigüedades.

\section{Tabla catálogo soporte}

Esta tabla sirve para señalar el tipo de soporte material que se utiliza para transmitir la relación. La tabla está conformada por un campo, mismo que indica el nombre del soporte. Son cinco los tipos de material consignados: papel, pergamino, tela, material no mencionado, sin material. El penúltimo se usa cuando se sabe que la relación cuenta con un soporte material, pero éste no se menciona de manera explícita; el último campo se emplea para la mayoría de las relaciones, pues casi siempre la transmisión se brinda de manera oral.

\section{Tabla tipo de acción}

Esta tabla sirve para indicar el tipo de acción que se lleva a cabo en la relación. Sólo está conformada por un campo en el que se brinda el nombre de las categorías. Son nueve tipos de acciones registradas: 1) humanas - cuando las acciones se limitan a la problemática dramática en curso - , 2) sobrenaturales, 3) divinas, 4) naturales, 5) imaginarias - cuando las acciones pertenecen al ámbito onírico, cuando la información es inventada o ha sido tergiversada, etc.- , 6) de origen histórico, 7) de origen literario, 8) de origen tradicional, y 9) de origen bíblico. Las relaciones pueden pertenecer a más de una categoría.

\section{Tabla versificación}

En esta tabla se describe el tipo de versificación utilizada para la transmisión del género discursivo. Es importante mencionar que una relación se puede expresar mediante diferentes tipos de versificación, existen, por ejemplo, las que combinan hasta tres tipos diferentes. Como lo apuntamos en su momento, era costumbre que este discurso se expresara en romances o en octavas, según lo había propuesto Lope de Vega en su Arte nuevo; sin embargo, la base de datos permite observar una gran variedad. Hasta el momento, se han registrado 24 diferentes formas de versificar este discurso: 1) décimas espinelas, 2) endecasílabos, 3) octavas, 4) octavas reales, 5) quintillas, 6) redondillas, 7) catorce formas de romance ( $a-a, a-e, a-o, e-a, e-e, e^{-}-0, i-a, i-e, i-0, o-a, o^{-} e$, o-o, $u-a, u-o), 8)$ sexteto-lira, 9) sextetos, 10) silva y 11) silva pareada. Cabe señalar que también existe la opción "sin versificación", que se utiliza cuando la relación se ofrece en prosa. 


\section{Emiliano Gopar Osorio}

\section{Relación entre las tablas}

Cada tabla catálogo contiene un campo reservado para un Id, que sirve para numerar los registros correspondientes. En el caso de la tabla catálogo Clasificación, por ejemplo, cada una de las diez categorías tiene su propio Id; a su vez, cada tabla relacional está compuesta por tres elementos. Véase, como ejemplo, la siguiente ilustración:

\begin{tabular}{|c|c|c|c|}
\hline \multicolumn{4}{|c|}{ 曺 Tx_clasificacion $x$} \\
\hline Id & IdTexto & - idClasificacic & Haga clic para agregar \\
\hline 1 & & 1 & 4 \\
\hline 2 & & 2 & 2 \\
\hline
\end{tabular}

Ilustración 1

La primera columna indica el Id de la tabla relacional, el cual no cumple con otra función más que la de enumerar los vínculos realizados. La segunda y tercera columna señalan, respectivamente, el Id_Texto y el Id de la tabla catálogo; la ilustración muestra el vínculo entre la tabla principal y la tabla catálogo Clasificación. Como se mencionó en su momento, el Id_Texto asigna un número irrepetible y único a cada relación; el Id_Clasificación remite, por su parte, a una categoría específica. Al colocar un Id en cada columna, se logra el vínculo entre una relación y la información de la tabla catálogo particular. En el sombreado de la Ilustración 1, se observa que la relación contenida en el Id_Texto 1 pertenece a la categoría 4 de la tabla catálogo Clasificación.

El panorama general de los vínculos entre la tabla principal y la tabla catálogos se puede apreciar en la siguiente ilustración:

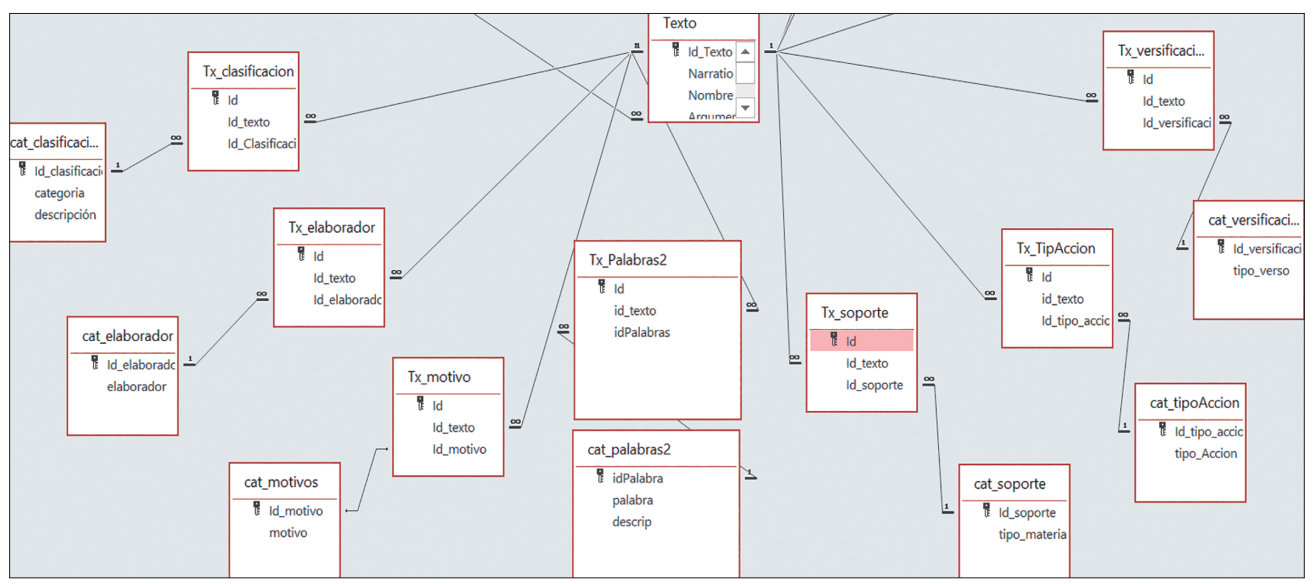

Ilustración 2 


\section{"Relaciones de comedias en la Nueva España, siglos xvi y xvII"}

En la parte central superior se observa la tabla Texto. En la imagen, las tablas catálogos están más alejadas de la tabla Texto y se ubican de izquierda a derecha en este orden: Clasificación, Elaborador, Motivo, Palabras clave, Soporte, Tipo acción y Versificación. ${ }^{31}$ Cada una de ellas está vinculada con la tabla principal mediante su correspondiente tabla relacional, las cuales se muestran en esta ilustración en la parte intermedia y conservan el mismo orden que las tablas catálogo.

\section{Utilidad de los datos proporcionados en la tabla Signos actorales}

Una búsqueda que tome en cuenta los datos recabados en la tabla catálogo Signos actorales puede ayudar a ampliar nuestros conocimientos en torno a la dialéctica entre el texto dramático y el espectacular cuando hay una transmisión de una relación, pues los datos ahí contenidos brindan indicios de la participación activa de los personajes durante esa situación comunicativa. Los resultados de esta búsqueda, por el momento, quedan pendientes para un estudio en el que actualmente estoy trabajando; sin embargo, ofrezco a continuación un breve ejemplo de los signos dramáticos lexicalizados y no lexicalizados obtenido de una relación que fue consignada en la base de datos bajo la denominación 02_MdCS_gallardoespañol, y que pertenece a la obra cervantina El gallardo español.

Antes del análisis del caso concreto, conviene señalar que desde la perspectiva de la semiótica, Díez Borque considera que la palabra posee un valor polisémico, mientras que las posibilidades escénicas son limitadas. Por tal motivo, es frecuente que "cuando se trata de acciones que no pueden ser indicadas por signos del texto $b$ la palabra sustituye a todos estos signos" (Díez, 1975: 65). ${ }^{32}$ Ante tal afirmación, cabe preguntar si realmente se puede hablar de una transitoria sustitución del texto dramático por el texto espectacular. ${ }^{33}$

El mismo Díez Borque advierte la dificultad implícita para desarrollar en escena el cambio de color en el rostro, un detalle actoral poseedor de un significado preciso y reconocido en la época. Para ello, ofrece el caso excepcional de una actora que

${ }^{31}$ Cabe señalar que en la Ilustración 2 no aparecen las tablas catálogos Princeps ni Bibliografía en virtud de que éstas se vinculan mediante la tabla relacional Princeps_Bibliografía, como en su momento se mencionó.

${ }^{32}$ En la terminología utilizada por José María Díez Borque, el texto a es "el texto de la obra", las palabras, mientras que el texto $b$ es "el texto escénico", el que le da especificidad teatral (Díez, 1975: 53). Los conceptos propuestos por Díez Borque son respectivamente equivalentes a los términos texto literario y texto espectacular empleados por María del Carmen Bobes Naves (Bobes, 1997: 32).

33 Tómese en cuenta que el estudioso ha señalado que los signos del texto $b$ no sólo sustituyen, sino que pueden subrayar o contradecir los signos del texto a (Díez, 1975: 66). 


\section{Emiliano Gopar Osorio}

dominaba a la perfección esta técnica: "La Riquelme [...] cuando representaba mudaba, con admiración de todos, el color del rostro, porque si el poeta narraba sucesos prósperos y felices, los oía con semblante todo sonrosado y si algún caso infausto y desdichado, luego se ponía pálida y en este cambiar de afectos era tan única que era inimitable" (J. Caramuel citado en Díez, 1975: 66).

En el fragmento se puede apreciar a la actriz como sujeto activo al recibir un relato, de ahí la admiración del público. Puede decirse, entonces, que durante la transmisión verbal no desaparece el texto espectacular, ocurre, más bien, que la información verbal se refuerza mediante los gestos actorales.

Desde el texto dramático es posible deducir signos dirigidos al texto espectacular, como se podrá observar en la relación cervantina que utilizamos en este espacio a modo de ejemplo. En ella, Oropeza cuenta a Arlaxa las hazañas bélicas del valiente don Fernando. En la relación se lee entre líneas la euforia que se tendría que hacer patente durante la transmisión del discurso. ${ }^{34}$ Uno de los signos no lexicalizados que denota tal estado de ánimo se ofrece mediante una referencia apelativa al espectador interno:

Oropeza.
de tierra, que se le antoja
dar sobre él: ved qué batalla
tan nueva y tan peligrosa (II: vv. 1157-1160).

Si tomamos en cuenta que una relación surge por la necesidad de ampliar el tiempo y el espacio, podemos inferir que, durante la transmisión, Oropeza tendría que alternar su mirada entre dos puntos: uno, los ojos de Arlaxa; la dirección de la mirada hacia este punto implica solicitar con mayor énfasis la atención de la dama y, al mismo tiempo, marca el vínculo con el aquí y ahora de la acción dramática. El otro punto es indeterminado: los corredores laterales, los aposentos, los desvanes o el patio del corral de comedias - lugares todos estos ocupados por el público - ; pasear la mirada por dichos espacios implica reforzar la creación de las acciones evocadas. Durante un lapso considerable, el caballero dirigiría su mirada hacia esos puntos indeterminados para poder así recrear imaginariamente la lejanía de las acciones marinas que va evocando; los movimientos de sus manos también seguirían la dirección de la mirada hacia esos espacios para reforzar la creación imaginaria de los lugares, objetos y personas que van poblando su narración. Pero los escasos momentos en que Oropeza interrumpe su relato implican guiños estratégicos para despertar admiración en la

\footnotetext{
${ }^{34}$ Recuérdese que la obra pertenece a las Ocho comedias que Cervantes dio a la imprenta y que nunca fueron escenificadas. De ahí la necesidad de referirnos a la virtualidad de la representación.
} 


\section{"Relaciones de comedias en la Nueva España, siglos XVI y xvII"}

dama; así ocurre en la cita anterior ("ved qué batalla/ tan nueva y tan peligrosa"), en la que se advierte el grado de peligrosidad en las hazañas del gallardo español. Para ello, la mirada, los movimientos de manos y la voz tendrían que cambiar de rumbo: ahora se fijarían en su oyente, Arlaxa.

Sin embargo, los movimientos del transmisor no se limitan a despertar en el otro un sobresalto; su persona misma parece experimentar una alteración repentina con su relato:

Oropeza. Salió a tierra y della un salto dio al bajel, cosa espantosa, que piensa el turco que el cielo cristiano llueve, y se asombra (II: vv. 1177-1180).

Recuérdese que en la época una de las acepciones del término espantar era causar admiración (Covarrubias, 1611: 375). En este caso, dicho asombro ("cosa espantosa") corresponde no a los turcos, los personajes de la diégesis, sino al mismo Oropeza, quien experimenta ese estado de ánimo al transmitir el relato; por tanto, debería ocurrir un cambio en la dirección de sus ademanes y gestos nuevamente hacia la mujer que recibe con agrado el relato. Además de este tipo de expresiones emocionales, la transmisión de la relación requiere cambios en la entonación de voz, tal como se puede deducir a partir de la siguiente cita:

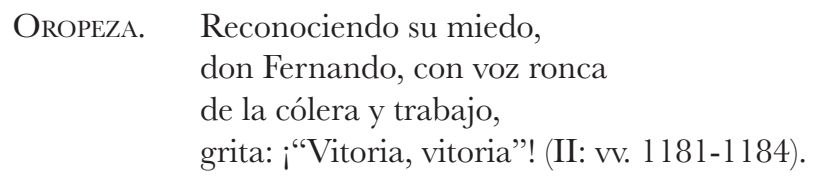

Es necesario que Oropeza cambie el tono de voz cuando transmite el grito de don Fernando para acompañar la contundencia de las palabras del caballero en contra de los turcos, pues aquí nos enfrentamos a un signo lexicalizado: el transmisor advierte que la voz de don Fernando es "ronca" a causa de la "cólera" y del "trabajo" (léase del esfuerzo). Además, señala el tono de la información verbal: "grita".

Si por parte del personaje transmisor se llevan a cabo movimientos, gestos y entonaciones de voz que denotan una activa participación actoral durante la transmisión de la relación, por parte del personaje receptor también se puede hablar de una participación igualmente activa a nivel actoral. Por lo menos así lo exigen los signos que indican la finalidad de Oropeza: causar asombro en Arlaxa, signos que se encuentran de manera lexicalizada en la fórmula de apertura: 


\title{
Emiliano Gopar Osorio
}

\author{
Oropeza. Escucha una [hazaña] \\ de su esfuerzo y fortuna, \\ que podrá ser que te asombre (II: vv. 1146-1 148; las cursivas son mías).
}

y de manera no lexicalizada en la fórmula de cierre:

\author{
$[\ldots]$ \\ Mira, Arlaxa, si ésta es obra \\ para que la fama diga \\ los bienes que dél pregona (II: vv. 1190-1192).
}

$\mathrm{Al}$ inicio y al final de la relación, las palabras de Oropeza invitan a la admiración. A pesar de la parquedad de la respuesta de Arlaxa (“iOh, qué famoso español!”), se puede comprobar que el efecto buscado por Oropeza se cumple, pues las palabras representan un signo no lexicalizado del reforzamiento de ese amor de oídas que agita el pecho de la dama y que en adelante causarán gran parte de las acciones en la obra.

Haría falta un estudio más amplio para ofrecer conclusiones sobre la actividad actoral durante la transmisión de la relación. No obstante, la muestra aquí expuesta permite observar que, al transmitir el género discursivo, el personaje puede echar mano de su técnica actoral para lograr persuadir o conmover a su escucha y no sólo esperar que la palabra sea la encargada de toda la tarea. Hay múltiples signos del personaje transmisor que desbordan la frontera del ámbito diegético y que se ubican momentáneamente en la acción dramática; al mismo tiempo, quien recibe el relato casi nunca permanece inamovible. A diferencia de lo que sucede en un texto del género narrativo, en el teatro los personajes que participan en una recreación de acciones diegéticas, como en el caso de la relación, no desaparecen del espacio mimético. En este sentido, podemos hablar no de una sustitución del texto espectacular por el texto dramático, sino de una dialéctica compleja entre ellos.

Algunos de los aportes que se esperan de la base de datos descrita en este trabajo son los siguientes. Primero, la reunión, en un mismo espacio, de diversas relaciones provenientes de textos que cuenten con una edición moderna, así como de textos inéditos que previamente serán editados con apego a una metodología de la crítica textual. Segundo, la clasificación del discurso basada en un criterio que tome en cuenta la especificidad genérica del teatro: la cuestión espacial. Tercero, la descripción pormenorizada de los elementos discursivos y espectaculares, muchos de los cuales no han tenido la suficiente atención por parte de los especialistas. Cuarto, la identificación de los elementos mediante los cuales se vincula la relación con la acción dramática. Quinto, la posibilidad de hacer búsquedas a partir de entradas diversas: por palabras, por motivos, por temas, por autor... 


\section{"Relaciones de comedias en la Nueva España, siglos xvı y xvıı"}

Es necesario advertir que el trabajo realizado hasta el momento tiene un carácter mecánico y descriptivo, sin embargo, también ha generado la observación aguda del fenómeno examinado. Espero, por un lado, haber llamado la atención sobre aspectos de la relación que han sido poco estudiados, y, por otro, que la descripción ofrecida en este artículo sirva para propiciar futuras investigaciones filológicas a partir de esta herramienta digital.

\section{Bibliografía}

Arellano, Ignacio

"Valores visuales de la palabra en el espacio escénico del Siglo de Oro", en Revista Canadiense de Estudios Hispánicos, volumen 19, número 3 (1995), 411-443.

ARISTÓteles

Poética. Traducción de Valentín García Yebra. Madrid: Gredos, 1974.

BAJTín, Mijail

Estética de la creación verbal. Traducción de Tatiana Bubnova. México: Siglo XXI, 1999.

Bobes Naves, María del Carmen

Semiología de la obra dramática. Madrid: Arco Libros, 1997.

CASA, Frank P. et al. (directores)

Diccionario de la comedia del Siglo de Oro. Madrid: Castalia, 2002.

Cervantes Saavedra, Miguel de

El gallardo español, en Florencio Sevilla Arroyo y Antonio Rey Hazas (edición, introducción y notas). Teatro completo. Barcelona: Planeta, 1987, 15-106.

Cortés Ortiz, Gecilia A.

"Diseño de la base de datos de sermones impresos durante el siglo XVII en la Nueva España”, en (an)ecdótica. México: Universidad Nacional Autónoma de México, Instituto de Investigaciones Filológicas, Seminario de Edición Crítica de Textos, volumen III, número 2 (2019), 121-138.

Corvin, Michel

"Contribución al análisis del espacio escénico en el teatro contemporáneo", en María del Carmen Bobes Naves (compiladora). Teoría del teatro. Traducción de Jesús G. Maestro. Madrid: Arco Libros, 1997, 201-228.

Govarrubias Orozco, Sebastián de

El tesoro de la lengua castellana o española. Madrid: Impresor Luis Sánchez, 1611. Consultado en: https://archive.org/details/A253315/page/n13/mode/2up [18/12/2019]. 


\section{Emiliano Gopar Osorio}

Gueva, Juan de la

Ejemplar poético, en El infamador. Los siete infantes de Lara. Ejemplar poético. Madrid: Espasa-Calpe, 1941, 117-169.

Diccionario de Autoridades

Real Academia Española. Tomo V, 1737. Consultado en: http://web.frl.es/DA.html [22/12/2019].

Díez Borque, José María

"Aproximación semiológica a la escena del teatro del Siglo de Oro español", en José María Díez Borque y Luciano García Lorenzo (editores). Semiología del teatro. Barcelona: Planeta, 1975, 49-92.

García de Enterría, María Cruz

Sociedad y poesía de cordel en el Barroco. Madrid: Taurus, 1973.

Gillet, Joseph E.

"A Neglected Chapter in the History of the Spanish Romance", en Revue Hispanique, tomo 56, número 130 (1922), 434-457.

"A Neglected Chapter in the History of the Spanish Romance. Postcript", en Revue Hispanique, tomo 60, número 137 (1924), 37-40.

GonzÁlez, Aurelio

"La creación del espacio. Mecanismo dramático en el teatro del Siglo de Oro", en Anthony J. Close y Sandra María Fernández Vales (editores). Edad de oro cantabrigense: Actas del VII Congreso de la Asociación Internacional del Siglo de Oro. Frankfurt/Madrid: Iberoamericana/ Asociación Internacional del Siglo de Oro, 2006, 61-76.

GonzÁlez Canal, Rafael

"Las relaciones de comedias de Rojas Zorrilla", en Aurelio González et al. (editores). Cuatro triunfos áureos y otros dramaturgos del Siglo de Oro. México: El Colegio de México/Universidad Autónoma Metropolitana/Asociación Internacional de Teatro Español y Novohispano de los Siglos de Oro, 2010, 15-40.

López Pinciano, Alfonso

Philosophia antigua poética. Tomo II. Edición de Alfredo Carballo Picazo. Madrid: Consejo Superior de Investigaciones Científicas, 1953, epístola 8, 301-385.

Marín, Diego

Uso y función de la versificación dramática en Lope de Vega. Valencia: Castalia, 1962.

Mignolo, Walter

"Cartas, crónicas y relaciones del descubrimiento y la conquista", en Luis Íñigo Madrigal (coordinador). Historia de la literatura hispanoamericana, época colonial. Tomo I. Madrid: Cátedra, 1982, 57-116.

144 (an)ecdótica vol. V, núm. 2, julio-diciembre 2021 


\section{"Relaciones de comedias en la Nueva España, siglos xvı y xvıı"}

Molt, Jaime

"Un tomo facticio de pliegos sueltos y el origen de las 'Relaciones de comedias"”. Alicante: Biblioteca Virtual Miguel de Cervantes, 2011. Consultado en: http://www.cervantesvirtual. com/nd/ark:/59851/bmcth939 (edición digital a partir de Segismundo, 23-24, 1976, 143167) $[17 / 12 / 2019]$.

Pavis, Patrice

Diccionario del teatro. Dramaturgia, estética, semiología. Barcelona: Paidós, 1980.

Pérez, Luis Celestino y Federico Sánchez Escribano

Afirmaciones de Lope de Vega sobre preceptiva dramática a base de cien comedias. Madrid: Consejo Superior de Investigaciones Científicas, 1961 (Anejos de Revista de Literatura, 17).

Pimentel, Luz Aurora

El relato en perspectiva. Estudio de teoría narrativa. México: Universidad Nacional Autónoma de México/Siglo XXI, 2002.

Rodríguez Cuadros, Evangelina

El actor español en el Barroco. Hipótesis y documentos. Madrid: Castalia, 1998.

UBERSFELD, Anne

Semiótica teatral. Traducción de Francisco Torres Monreal. Madrid: Cátedra/Universidad de Murcia, 1998.

Vega, Félix Lope de

Las fortunas de Diana, en Juan Coronado (editor). Dos novelas a Marcia Leonarda. México: Universidad Nacional Autónoma de México, 2003, 1-64 (Relato Licenciado Vidriera, 2).

Arte nuevo de hacer comedias. Edición de Enrique García Santo-Tomás. Cátedra: Madrid, 2009.

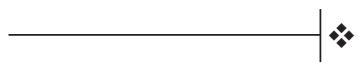

